Territorios 32 / Bogotá, 2015, pp. 81-95

ISSN: 0123-8418

ISSNe: 2215-7484

Procesos de ocupación del territorio, historia urbana y patrimonio (I)

\title{
Estrategias de ordenamiento territorial en los centros históricos colombianos
}

Strategies of Territorial Ordering in the Colombian Historical Centers

Estratégias de ordenamento territorial nos centros históricos colombianos

Margarita María Rodríguez Garcés*

Recibido: 12 de diciembre de 2013

Aprobado: 5 de febrero de 2014

Doi: dx.doi.org/10.12804/territ32.2015.04

Para citar este artículo:

Rodríguez, G. M. M. (2015). Estrategias de ordenamiento territorial en los centros históricos colombianos. Territorios, 32, 81-95. Doi: dx.doi.org/10.12804/territ32.2015.04

* Arquitecta de la Universidad Pontificia Bolivariana, Medellín. Especialista en Planeación Urbano-Regional y magister en Estudios Urbano-Regionales de la Universidad Nacional, Medellín. Escuela de Planeación Urbano-Regional, Universidad Nacional de Colombia, sede Medellín. Correo electrónico: margaritamrg@gmail.com 
Palabras clave

Centros históricos, ordenamiento territorial, equilibrio entre memoria $y$ futuro, estrategias de gestión y financiación, tratamientos urbanísticos, apropiación sociocultural, oferta turistica.

Keywords

Historical centers, territorial ordering,

balance between memory and future, strategies of management and financing, urban treatments, socio-cultural appropriation, touristic offer.

Palavras-chave Centros Históricos, Ordenamento Territorial, Equilibrio entre Memória e Futuro, Estratégias de Gestão e Financiamento, Tratamentos Urbanísticos, Apropriação Sociocultural, Oferta turística.

\section{territarias 32}

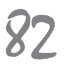

\section{RESUMEN}

Respecto del manejo de los Centros Históricos con Declaratoria Nacional, en relación con el Ordenamiento Territorial Urbano de los municipios a los que pertenecen, se comprueba que en cumplimiento de la Ley 388 de 1997 solamente las categorías de Plan de Ordenamiento Territorial (POT) y Plan Básico de Ordenamiento Territorial (PBOT) incorporan el tema de conjuntos históricos, como si ningún municipio con Esquema de Ordenamiento Territorial (EOT), y menos de 30000 habitantes, tuviera Centro Histórico. Esto requiere más que la aplicación asilada de la Ley de Cultura 397 de 1997, mediante el Plan Especial de Manejo Patrimonial (PEMP), siendo necesario ajustar el alcance de los contenidos urbanos de los POT, PBOT y especialmente EOT de los municipios con Centros Históricos, para garantizar su protección. Por lo tanto, los PEMP no pueden ser los receptores de las carencias de los POT, PBOT y EOT, sino que estos últimos deben desarrollar el tema patrimonial. Adicionalmente, como la ciudad es histórica pero también es dinámica, se plantean otras estrategias espaciales y económicas para la protección de los Centros Históricos, como la definición de distintos tratamientos urbanísticos y la implementación de instrumentos de gestión y financiación, además del fortalecimiento de la oferta turística como estrategia de competitividad de los municipios a los que pertenecen estos centros históricos, con iniciativas de apropiación cultural y desarrollo social y económico local.

\section{ABSTRACT}

Regarding to Historical Centers with National Declaration in relation to the "urban territorial ordering" of the municipalities to which they belong, it is confirmed that complying with Law 388/97 only the categories Territorial Ordering Plan (Plan de Ordenamiento Territorial - POT) and Territorial Ordering Basic Plan (Plan Básico de Ordenamiento Territorial - PBOT) include the subject of historical ensemble; as if no municipality with (Territorial Ordering Outline (Esquema de Ordenamiento Territorial-EOT) and less than 30.000 inhabitants had a Historical Center. This requires more than the "isolated application" of the Culture Law 397/97 through the Special Plans of Patrimonial Management (Plan Especial de Manejo Patrimonial - PEMP), being necessary to adjust the scope of the urban contents de the POT, PBOT and especially EOT of the municipalities with Historical Centers giving guarantee to its protection. Therefore, the PEMPs cannot be receptors of the lack of coverage of the POT, PBOT and EOT, but these last ones should develop the patrimonial topic. Besides, as "the city is historical but also dynamic", other spatial and economic strategies are posed for the protection of the Historic Centers; such as the definition of the different urban treatments and the implementation of management and financing instruments; as well as the strengthening of the "touristic offer" as a competitive strategy of the municipalities to which they belong, with cultural appropriation initiatives and, local economic and social development.

\section{RESUMO}

Respeito ao manejo dos Centros Históricos com Declaratória Nacional em relação ao "ordenamento territorial urbano" dos municípios aos que pertencem, comprova-se que em cumprimento da Lei 388/97 somente as categorias de POT e PBOT incorporam o tema de conjuntos históricos; como se nenhum município com EOT e menos de 30.000 habitantes tivesse Centro Histórico. Isto requere 
mais que a "aplicação asilada” da Lei de Cultura 397/97 mediante os PEMP, sendo necessário ajustar o alcance dos conteúdos urbanos dos POT, PBOT e especialmente EOT dos municípios com Centros Históricos garantindo sua proteção. Pelo tanto, os PEMP, não podem ser os receptores das carências dos POT, PBOT e EOT, senão que estes últimos devem desenvolver o tema patrimonial. Adicionalmente, como "a cidade é histórica mas também é dinâmica”, apresentam-se outras estratégias espaciais e económicas para a proteção dos Centros Históricos; tais como a definição de distintos tratamentos urbanísticos e a implementação de instrumentos de gestão e financiamento; além disso, o fortalecimento da "oferta turística” como estratégia de competitividade dos municípios aos que pertencem, com iniciativas de apropriação cultural e, desenvolvimento social e econômico local.

\section{Introducción ${ }^{1}$}

En Colombia, se están formulando Planes de Ordenamiento Territorial desde hace quince años, y es ahora cuando se puede evaluar su efectividad. En este momento surge una preocupación específica respecto del manejo de los Centros Históricos con Declaratoria Nacional, en cuanto a su articulación con el ordenamiento territorial urbano de los municipios a los que pertenecen y especialmente en relación con sus instrumentos de gestión y financiación.

En el territorio nacional se han declarado 44 Centros Históricos, siete de ellos se encuentran en Antioquia (ver figuras), el de Rionegro (que más adelante se presenta como estudio de caso) cuenta con POT, el de Marinilla con PBOT y los de Santa Fe de Antioquia, Jardín, Jericó, Abejorral y Concepción con EOT. Estos últimos cinco, específicamente, según la Ley 388 de 1997 y su Decreto 879 de 1998, no tienen la obligación de incorporar el manejo patrimonial de sus Centros Históricos al ordenamiento territorial.

Por otra parte, la Ley 397 de 1997 (General de Cultura) establece que para la planeación y gestión de los Bienes de Interés Cultural -(BIC) de carácter nacional - antes denominados Monumento Nacional y que pueden ser edificaciones individuales o conjuntos urbanos-, entre los que se encuentran los Centros Históricos, el instrumento es el Plan Especial de Protección, nombre modificado en la Ley 1185 de 2008 por Plan Especial de Manejo

Figura 1. Centro Histórico - Santa Fe de Antioquia

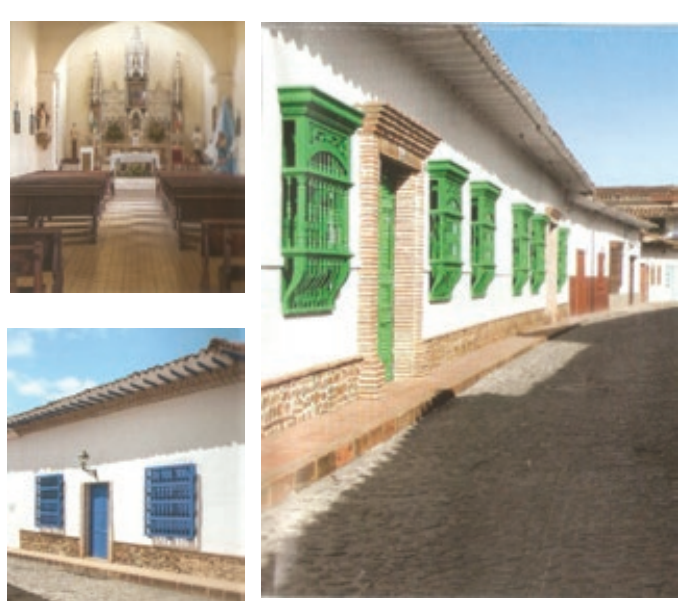

Fuente: Red Turística de Pueblos Patrimonio (2010). Un viaje en el tiempo [Folleto]. Bogotá: MinCIT y FONTUR Colombia.
${ }^{1}$ Este artículo es producto de trabajo de la asignatura de Economia que hace parte del pénsum de la Maestría en Estudios Urbano-Regionales de la Universidad Nacional de Colombia, sede Medellín. territarias 32

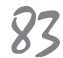


Figura 2. Centro Histórico - Jericó, Antioquia
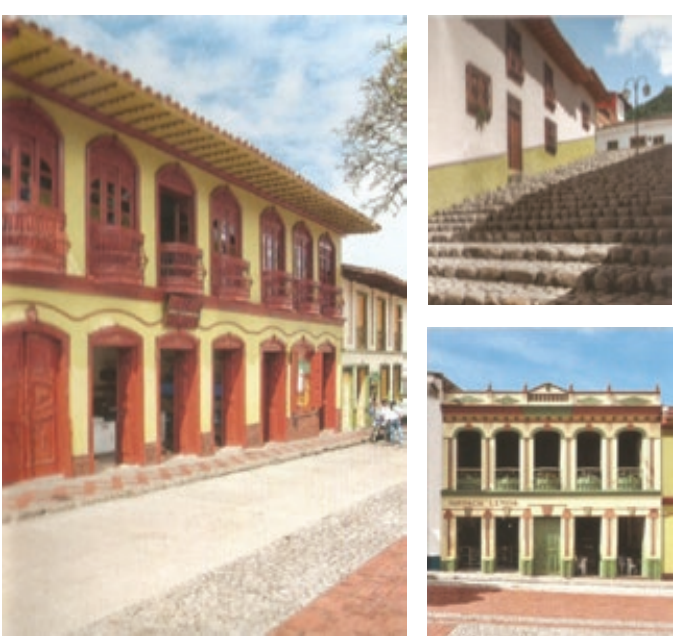

Fuente: Red Turística de Pueblos Patrimonio (2010). Un viaje en el tiempo. [Folleto]. Bogotá: MinCIT y FONTUR Colombia.

y Protección, (en esta modificación hacen referencia al tema de manejo por la nueva incorporación de instrumentos de gestión). Sumado a lo anterior, la Ley 1185 de 2008 también ratificó que los BIC inmuebles, como son los Centros Históricos, mediante sus PEMP deberán ser incorporados al POT del municipio al que pertenecen y someterse a los procedimientos legales establecidos para su revisión o modificación, según sea el caso.

En cuanto a la estructura temática de los PEMP, se deben seguir las orientaciones metodológicas del Manual del Ministerio de Cultura (2011), que establece algunos pasos para su formulación, primero, el análisis y diagnóstico, que incluye la valoración histórica, físico-espacial, socio-económica territarias 32 84 propuesta integral, que apunta a la conservación y sostenibilidad del BIC, de tal manera que potencie las fortalezas, aproveche las oportunidades, solucione las debilidades y elimine o mitigue las amenazas. Luego de esto, el PEMP deberá ser revisado y aprobado por el Ministerio de Cultura para proceder a su adopción mediante Resolución.

Así las cosas, se puede decir que la preocupación planteada toma mayor fuerza en la actualidad, pues el Decreto 763 de 2009 , que reglamenta el Patrimonio Cultural de la Nación de naturaleza material, establece que en 2014 todos los BIC de carácter nacional deben tener PEMP, lo cual está muy distante de la realidad, pues ni siquiera Bogotá como capital de la Nación cuenta todavía con un PEMP aprobado.

\section{Normativa de los Centros Históricos en los POT y PDM}

Iniciando con los antecedentes legales, se encuentra que la Ley 388 de 1997, al establecer la obligatoriedad de todos los municipios del país de elaborar Planes de Ordenamiento Territorial, también define los contenidos que estos deben tener, según la población total del municipio. En consecuencia, se establecen tres categorías: POT para municipios con más de 100000 habitantes, PBOT para municipios con población total entre 30000 y 100000 habitantes y EOT para municipios con menos de 30000 habitantes, $y$, a la vez, ordena sus contenidos en los componentes general, urbano y rural.

Margarita María Rodríguez Garcés 
Esta categorización y sus contenidos se concretan en el primer decreto reglamentario de la Ley 388 de 1997 que es el Decreto 879 de 1998. De ambos se concluye que no le dan suficiente significación a los Centros Históricos y que solo establecen la delimitación de los conjuntos urbanos históricos y culturales en los Componentes Urbanos de los POT y los PBOT, como si ningún municipio con menos de 30000 habitantes tuviera Centro Histórico.

Sin embargo, aunque las propuestas y normas aprobadas en el POT deberán estar articuladas al PEMP y el objetivo es garantizar la coherencia y complementariedad entre estos instrumentos de planeación y gestión, la Ley 388 de 1997 establece que las normas de protección del patrimonio cultural son de superior jerarquía y, por lo tanto, priman sobre otras normatividades locales. De esta manera, en el caso de existir diferencias entre el POT y el PEMP de los Centros Históricos con declaratoria nacional, primarán las disposiciones consignadas en este último.

Siguiendo la línea de las determinaciones legales y los instrumentos técnicos en el nivel local, se formulan los Planes de Desarrollo Municipal (PDM) y los Planes Municipales de Cultura, ambos con la posibilidad de incorporar las decisiones del PEMP. Especialmente los PDM, reglamentados por la Ley 152 de 1994 (Ley Orgánica del Plan de Desarrollo), pueden materializar las disposiciones de ordenamiento territorial y protección patrimonial, así como aquellas complementarias de ámbitos no físico-espaciales, pues estos deben definir las acciones que se realizarán en el corto, mediano y largo plazo de cada periodo de gobierno local, comprometiendo sus fuentes de financiamiento.

En sí, los PDM deben incorporar estrategias de desarrollo económico local y, en el caso de los Centro Históricos, las estrategias espaciales deben apuntar a que dichos sectores patrimoniales sean atractivos para fortalecer la competitividad de los municipios a los que pertenecen.

\section{Estrategias espaciales de los Centros Históricos para la competitividad municipal}

La hipótesis de que la condición de Centro Histórico, con la Declaratoria Nacional (ya sea con o sin PEMP aprobado), sea una variable de Desarrollo frente a Crisis es el punto de partida para la siguiente reflexión. Primero, se hará referencia a la crisis como producto de las declaratorias patrimoniales aplicadas sin concertación con la comunidad y, luego, se señalarán estrategias para el manejo de los Centros Históricos como una variable de desarrollo económico.

La crisis de los Centros Históricos colombianos no surge en el momento de su declaratoria, lo cual es viable desde la Ley 05 de 1940, sino cuando con la Ley 09 de 1989 (Reforma Urbana) se empiezan a formular Planes de Desarrollo Municipal con enfoque físico-espacial, esto teniendo en cuenta la preexistencia de la Ley 61 de 1978 (Ley Orgánica de Desarrollo Urbano).

A partir de dicho periodo, ubicado en los años noventa, los municipios empren- territarias 32

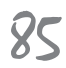


den la formulación de una serie de instrumentos de planeación referidos a normativas de uso y ocupación del suelo, que para los Centros Históricos con Declaratoria Nacional básicamente consistían en su congelamiento. Con la aparición de presiones opuestas ejercidas por ocupantes del espacio público, propietarios e inversionistas.

Esta contraposición desencadenó en la destrucción acelerada de los Centros Históricos y en una negativa trasformación de la imagen de los elementos constitutivos de conjuntos patrimoniales, pues las herramientas técnicas de control no eran suficientes y los llamados opositores procedieron a trasformar los inmuebles patrimoniales con obras de adición y subdivisión, incluso de demolición, para garantizar su aprovechamiento, ya que hasta el momento no se aplicaban incentivos ni la figura de compensación. Por ejemplo, en los Centros Históricos de los municipios de Jardín y Jericó en Antioquia, las Oficinas de Planeación constataron la demolición, inducida por sus propietarios, de inmuebles con declaratoria de conservación, con el único propósito de no congelar la renta y dejarlos como lotes valorizables por quedar aptos para nuevos aprovechamientos con diseños, espacios y materiales modernos.

Como factor de crisis asociado con los Centros Históricos, está la tendencia a una inadecuada utilización del espacio público, en cuanto a amoblamiento, movilidad y ventas ambulantes, lo que ha conllevado a la necesidad de crear políticas económicas y sociales para evitar su deterioro. Esta situación le ha demostrado a instancias superiores, como el Ministerio de Cultura (anteriormente Colcultura), que es indispensable incorporar la concertación con las comunidades como estrategia para garantizar la protección patrimonial, por lo cual la metodología del Manual del Ministerio de Cultura (2011), para la elaboración de PEMP, incorpora un Plan de Divulgación.

Otras estrategias orientadas a la protección patrimonial se refieren a la definición

Figura 3. Centro Histórico - Jardín, Antioquia

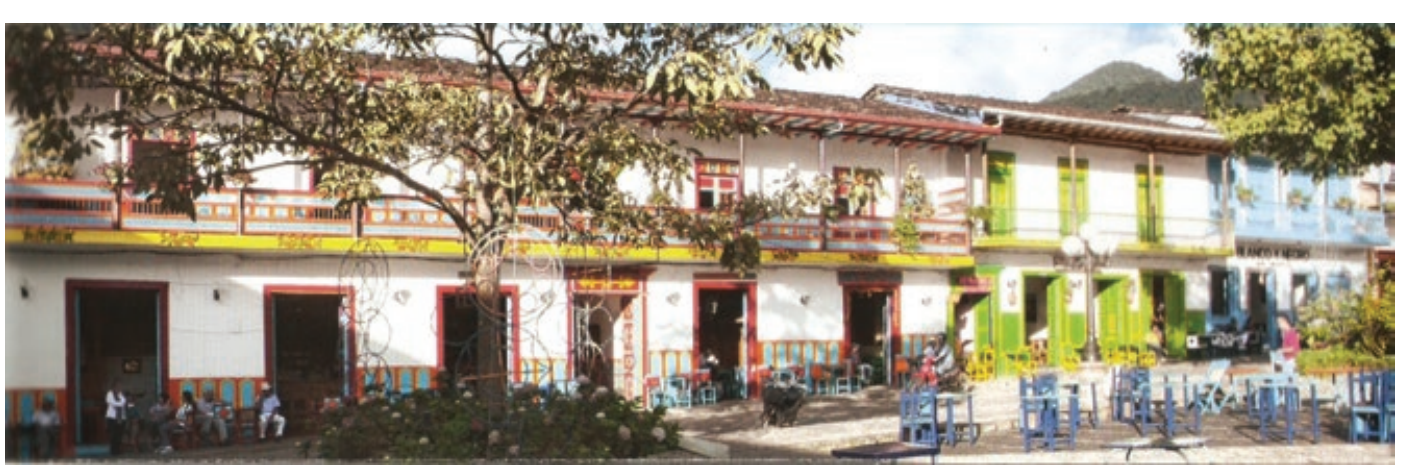

territorios 32

Fuente: Red Turística de Pueblos Patrimonio (2010). Un viaje en el tiempo. [Folleto]. Bogotá: MinCIT y FONTUR Colombia. 
de Tratamientos Urbanísticos en los POT, que en el caso de los Centros Históricos pueden ser principalmente de conservación, renovación o desarrollo. Cabe anotar que aquí solamente se hace referencia a tratamientos que se aplican a sectores urbanos y, específicamente, a aquellos patrimoniales, no al manejo de inmuebles individuales en su interior, ya sean predios o edificaciones. En estos casos, por ejemplo, se encuentran inmuebles (como parqueaderos) que requieren el manejo de desarrollo prioritario.

Por su parte, la Renovación Urbana está enmarcada en las nuevas políticas de competitividad económica, siendo esta una de las siete estrategias de la política urbana para optimizar el desarrollo urbano en $\mathrm{Co}$ lombia, según el Viceministerio de Vivienda y Desarrollo Territorial. En los Centros Históricos se requiere la incorporación de este tratamiento como estrategia para su recuperación y revitalización, mediante modificaciones sustanciales a los usos del suelo y de las edificaciones, pues por lo general son sectores urbanos con problemas de desorden social y deterioro físico cuya escala depende del tamaño de la ciudad en que se ubican.

Como definición técnica del tratamiento de renovación, se retoma la del POT de Medellín, que en su Artículo 240 dice que su objetivo es:

[...] promover importantes transformaciones en zonas que cumplen un papel fundamental en la consolidación del modelo de ordenamiento propuesto por el POT y en el cumplimiento de los objetivos del mismo y que por razones de deterioro ambiental, físico o social, conflicto funcional interno o con su entorno inmediato, requieren de esta transformación físico-espacial y socioeconómica para aprovechar al máximo su potencial. De esta manera, se busca que aprovechando su localización estratégica en la ciudad y sus excelentes condiciones de infraestructura de servicios públicos y movilidad, se promuevan procesos de intensificación y diversificación de la utilización del suelo y de las construcciones, a fin de lograr, entre otros fines, el mejoramiento integral de vida de los moradores, el aprovechamiento intensivo del suelo, la racional densificación y mezcla de usos, la descongestión del tráfico urbano o la conveniente rehabilitación de los bienes históricos y culturales. (2006, Art. 240).

Este cambio radical del uso del suelo debe cumplir a la vez una función social. Por ejemplo, en el sector El Cartucho en Bogotá (aunque no está dentro de los límites del Centro Histórico y este a su vez no tiene PEMP aprobado), la renovación no fue dirigida a su población más deprimida con proyectos de redensificación, por el contrario, el objetivo fue generar una nueva versión de turismo para clases altas y extranjeros. Este proceso se inició con la destrucción de El Cartucho, la expulsión de sus habitantes y la construcción de un parque, todo para la recuperación social y comercial del centro de la ciudad.

En los casos de los Centros Históricos de Lima y Quito, como ciudades latinoamericanas con problemas similares a los tersitarios 32 
colombianos, se encuentra que en Lima el repoblamiento de su Centro Histórico forma parte de la política de la Municipalidad. Allí, la estrategia de renovación ha incorporado acciones de restauración de inmuebles monumentales y la construcción de nuevas viviendas para la reubicación de familias, lo que hace que se respete el contexto monumental. Estas personas contarán con áreas destinadas al desarrollo de actividades económicas, vinculadas fundamentalmente al turismo (gastronomía, talleres artesanales, agencias de viajes, $\mathrm{Co}^{-}$ mercialización de recuerdos, etc.). Además, la población residente, al estar debidamente capacitada, participa formando parte de los equipos de carpintería, yesería, albañilería, etc. El resultado de la Renovación Urbana es que se han revalorizado sustancialmente los predios intervenidos.

Por su parte, en el Centro Histórico de Quito se incorporó un programa de rehabilitación, que tuvo como objetivo conservar y rehabilitar el patrimonio del Centro Histórico, esto logró que se le devolviera al área su importancia funcional, se revitalizaran las actividades comerciales y de servicios tradicionales, lo que facilitó el acceso a los bienes y servicios que ofrece y promovió el correcto uso y mantenimiento de los edificios públicos y privados, haciéndolo más atractivo para el visitante interesado en su acervo histórico y cultural.

Ahora, complementando la definición de renovación, también se retoma la de redesarrollo como concepto aplicable a los Centros Históricos. Según el Artículo 240 del POT de Medellín, aunque este con- cepto presenta similitudes con la definición que se le da al tratamiento de mejoramiento, el de redesarrollo:

Corresponde a las zonas homogéneas identificadas como áreas en transformación, y cuyo propósito de desarrollo es orientar procesos de transformación ya iniciados o generar nuevos en zonas con localización estratégica en la ciudad de acuerdo con los objetivos de ordenamiento propuestos por el POT, de manera que se privilegie su transformación hacia la optimización de su potencial, permitiendo mayores aprovechamientos y diversidad de usos (2006, Art. 240).

Por último, se hace referencia a la definición de conservación como tratamiento dirigido a sectores que deben mantener o recuperar sus valores ambientales y urbanos originales relevantes, en donde se respete armónica e integralmente el trazado vial, el espacio público, la morfología predial y la calidad ambiental y paisajística, siendo el caso de los Centros Históricos el que se manejará bajo una normativa especial, según los criterios de intervención para los inmuebles de conservación.

Según el Artículo 240 del POT de Medellín, el tratamiento de Conservación:

[... ] se aplica en las zonas homogéneas identificadas como sectores urbanos con valor urbanístico, arquitectónico y paisajístico. El objetivo de este tratamiento es la valoración, protección y recuperación de los sectores que cuentan con un conjunto de elementos significativos o altamente representativos de

Margarita María Rodríguez Garcés 
la evolución de la cultura arquitectónica y urbanística de la ciudad, procurando la preservación de sus características arquitectónicas, urbanísticas, morfológicas, ambientales y paisajísticas. Para ello, se establecen diversas limitaciones a la transformación de la estructura física, de espacios naturales y espacios públicos de edificaciones singulares y de conjuntos construidos y sectores de interés patrimonial en el municipio [...] acorde con las directrices definidas en el Plan Especial de Protección Patrimonial (2006, Art. 240).

Dicho PEMP de Medellín, como herramienta técnica para el manejo especial de los sectores con características patrimoniales no declarados Centros Históricos, estableció la siguiente categorización: sectores de conservación urbanística y arquitectónica, sectores de preservación urbanística y sectores de preservación del paisaje cultural rural. Los primeros corresponden a aquellos que mantienen sus atributos originales y conservan edificaciones de valor patrimonial. Los segundos conservan rasgos distintivos de sus atributos originales, constituyéndose en ejemplos de la historia del municipio. Y los terceros presentan evidencias materiales asociadas con modos de vida y técnicas constructivas tradicionales que les confieren valor cultural.

Ahora, al integrar los tratamientos de renovación y conservación en el ámbito colombiano, se podría hacer referencia a su aplicación en el PEMP del Centro Histórico de Santa Marta, uno de los tres planes piloto del Plan Nacional de Recuperación de Centros Históricos, cuyo objetivo no solamen- te es propiciar importantes inversiones en obras públicas, sino también generar entre la comunidad un sentido de apropiación hacia sus Centros Históricos, que se miran no solamente como espacios de conservación arquitectónica o patrimonial sino como ejes de desarrollo económico y social.

En Santa Marta, la estrategia espacial de incorporar en el Centro Histórico los tratamientos de Conservación del Patrimonio y Renovación Urbana ha suscitado la dinamización de los Bienes de Interés Cultural, al aprovechar su potencial para la generación de proyectos de alto impacto económico y social, además de la atracción de inversiones del sector privado, la producción de nuevas viviendas y dotaciones - a partir del desarrollo de proyectos en áreas de renovación-, la recualificación del sector con mejores condiciones de empleo e ingreso para la población residente y programas de gestión social y de protección a los moradores del centro. Aquí, se ha apuntado al objetivo principal de los PEMP, que es el mejoramiento de la calidad de vida por medio de la incorporación del patrimonio cultural a la dinámica económica y social.

A ese mejoramiento de la calidad de vida de la población, que también ha sido el objetivo principal de las iniciativas incorporadas en casi todas las experiencias de desarrollo local en América Latina, se refiere Antonio Vázquez Barquero (2007) en su obra Desarrollo Endógeno. El autor afirma que las políticas de desarrollo endógeno se basan en que los proyectos económicos y sociales que sean coordinados por medio de nuevas formas de gobernación en las que territarias 32 
participen los ciudadanos. Según este mismo autor, en la actualidad lo importante del desarrollo es la autonomía y el autodesarrollo con iniciativas locales basadas en la utilización de los propios recursos, tal como lo es el patrimonio cultural.

\section{La estrategia de los instrumentos de gestión y financiación}

Partiendo de la reflexión de Jordi Borja (2003) sobre "la ciudad y sus tres dimensiones" (pp. 35-70) en La ciudad conquistada, se debe buscar un equilibrio entre la memoria y el futuro, dignificando la ciudad presente, pues toda ciudad es histórica pero también es dinámica y sus elementos son susceptibles de conservarse, renovarse, reconvertirse o derribarse. En esta obra el autor expone "la ciudad pasada como presente y la ciudad futura como la que se está haciendo hoy" (pp. 40-46). Por lo tanto, no es suficiente la definición de tratamientos urbanísticos para asignar localizaciones, terrenos, infraestructuras, equipamientos y normas de ocupación y construcción, sino que es necesario que los POT abarquen desde su concepción general una visión de futuro construida sobre la historia y la apropiación sociocultural, hasta la implementación de estrategias futuras para la gestión y financiación de los Centros Históricos.

Por ejemplo, en el caso del Centro Histórico de Lima, las estrategias han consistido en la creación del Fondo Municipal de Renovación Urbana, que se ha constituido en el soporte financiero de este programa, además, en la recuperación de la plusvalía urbana, que se traslada a los grupos residentes, y en que los propietarios de inmuebles del Centro Histórico podrán redimir su deuda tributaria con la municipalidad de Lima al invertir en la recuperación de su propiedad.

Otras estrategias puntuales en Lima son la generación de espacios colectivos cubiertos, la mezcla de usos comerciales y residenciales, el aprovechamiento de soluciones espontáneas (altillos y adición de módulos de servicios), la sostenibilidad de cada edificio patrimonial como un microsistema urbano (reciclaje de residuos, vegetación en altura, etc.) y bonos de densificación en otras áreas de la ciudad.

En Colombia, la estrategia más utilizada tradicionalmente ha sido la exención parcial o total de impuestos, aunque los municipios han creado otras similares. Además, renace la esperanza de la conservación patrimonial de inmuebles y sectores con la aplicación de instrumentos de financiación, como es la figura de compensación por tratamiento de conservación, ya sea en dinero o por medio de la trasferencia de derechos de desarrollo y construcción (expuesta más adelante a manera de ejemplo con el caso de Rionegro, Antioquia).

Además, es importante recordar que en Colombia ya debe estar superada la etapa en la que la protección de los Centros Históricos dependía de la aplicación de normas que restringían, prohibían o congelaban — como en el caso de Bogotá-, y que en este momento los municipios deben trascender de decisiones normativas a la implementación de proyectos de restauración, 
Figura 4. Centro Histórico - Jardín, Antioquia

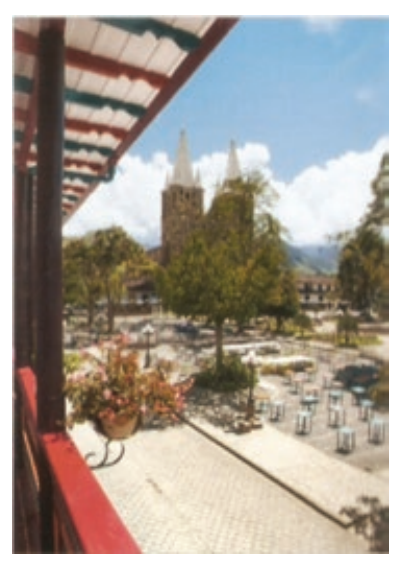

Fuente: Red Turística de Pueblos Patrimonio (2010). Un viaje en el tiempo. [Folleto]. Bogotá: MinCIT y FONTUR Colombia.

Figura 5. Centro Histórico - Concepción, Antioquia

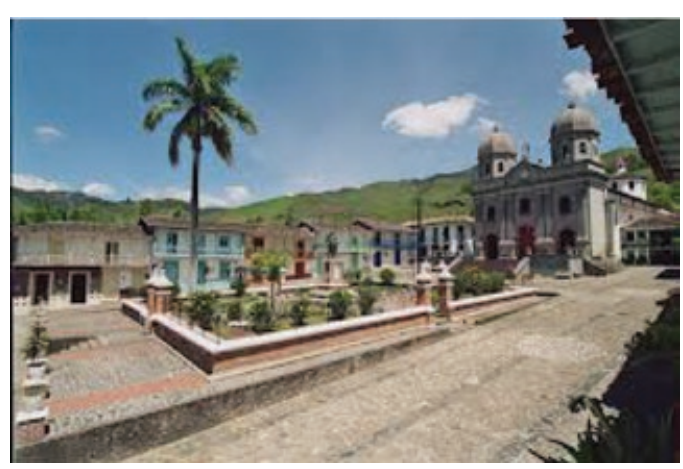

Fuente: Red Turística de Pueblos Patrimonio (2010). Un viaje en el tiempo. [Folleto]. Bogotá: MinCIT y FONTUR Colombia.

conservación, renovación o desarrollo de los sectores patrimoniales. Tales proyectos tendrán que estar viabilizados en los PDM, los cuales deben comprometer a las fuentes de financiamiento para ejecutar en cada periodo de gobierno local las respectivas acciones definidas en el POT y el PEMP, así como incorporar disposiciones complementarias de ámbitos no físico-espaciales.

Terminando con todas estas estrategias asociadas con los POT y PDM, se hace referencia a otra estrategia que deja el camino señalado para una nueva reflexión, pues ha estado demostrando su efectividad en cuanto a la protección del Patrimonio Cultural y es la posibilidad de asociar la conservación de los Centros Históricos con su aprovechamiento como oferta turística. Por ejemplo, en Quito, la estrategia del patrimonio en función del turismo ha consistido en la restauración de monumentos, la puesta en valor de conjuntos urbanos, un plan de inversiones para restauración y habilitación y la asistencia técnica y financiera para proyectos de conservación. Pero para consolidar todo esto como industria turística, el valor patrimonial no es suficiente $\mathrm{y}$ se requiere su adecuada utilización y articulación, cuyos beneficios económicos han generado que países europeos cuenten, entre sus principales fuentes de riqueza, a la protección de lo que denominamos en Colombia Bienes de Interés Cultural.

\section{La ciudad como oferta y la innovación urbanística}

A propósito de las estrategias de planeación, gestión y financiación para el patrimonio cultural, y retomando la idea de que los Centros Históricos deben ser atractivos para fortalecer la competitividad de los muni- territarias 32 
cipios a los que pertenecen, a continuación se retoman algunas afirmaciones de Jordi Borja (2003) sobre "la ciudad como oferta y la innovación urbanística” (pp. 71-118) en La Ciudad Conquistada.

La ciudad debe ser una oferta global, no de sectores aislados, no debe ofertar solo su imagen, sino sus realidades urbanas. En cuanto a las formas urbanas y los modos de intervención en la ciudad, ella expresa contradicción por su herencia y sus dinámicas. Por un lado, los Centros Históricos revalorados, museificados o gentrificados $\mathrm{y}$, por otro, la trama urbana difusa, fragmentada y privatizada. Se heredan tejidos urbanos obsoletos, con tramas originales y otras reconvertidas con nuevas actividades $\mathrm{y}$ funciones.

Las formas urbanas de la ciudad actual se caracterizan por la mezcla de morfologías en espacios que contienen tiempos y usos diferentes, tanto en las áreas consolidadas como de expansión urbana. Acá se consideran especialmente la diversidad de tramas y tipologías constructivas heredadas del pasado, que se mantienen en la ciudad actual. Por lo tanto, actualmente no existen modelos urbanos dominantes.

De esta manera, el futuro desarrollo de las ciudades tampoco puede someterse a un modelo preestablecido, y se plantean varios modos de intervención en la ciudad agrupados en tres líneas. Línea 1, Instrumentos de Intervención (planes estratégicos e integrales, proyectos urbanos, parques urbanos, proyectos a pequeña escala, trasformación de entornos sin ignorar la historia y renovación de zonas a partir de edificios emblemáticos). Línea 2, Estrategias Territoriales (nuevas centralidades, ciudad región, cambio de usos, revaloración del paisaje y desarrollo sostenible, espacio público y equipamiento monumental, festivalización del urbanismo y mixtura social). Línea 3, Cultura y Urbanismo (gestión estratégica, delimitación geométrica de territorios e intervenciones, proyectos y servicios urbanos, respuesta a la cultura urbanística acumulada con sus desafíos y demandas, debates sobre dinámicas urbanas que rompen el pasado o el conservacionismo que museifica la ciudad heredada, relaciones interinstitucionales y participación y solidaridad ciudadana).

Jordi Borja (2003) concluye que en la actualidad las corrientes más avanzadas de la arqueología y la museística consideran que toda la ciudad existente es historia y que el patrimonio heredado debe ser vivido y usado en el presente. Además, que la vida urbana con sus mezclas y densidades, tiene larga historia por delante.

\section{El caso de Rionegro, Antioquia como ejemplo de la incidencia del POT en su Centro Histórico}

El autor Jordi Borja (2003) en su obra La Ciudad Conquistada logra integrar los conceptos de patrimonio y territorio, es por ello que, en su reflexión sobre "la ciudad y sus tres dimensiones", (pp. 35-70) la ciudad histórica (mirada como sector urbano) es la ciudad de la memoria, la que trasmite la historia, la cultura y la identidad; es a la que en el imaginario se le atribuye 
una imagen simbólica, así como el valor de centralidad e integración ciudadana. Por lo tanto, el concepto de ciudad histórica generalmente coincide con el centro y algunos barrios que lo circundan. Así, los Centros Históricos o Sectores Fundacionales pueden cumplir el rol de centro de ciudad, los que concentran funciones institucionales, comerciales o de servicios y representan un valor excepcional por su urbanismo, arquitectura o historia. De otra parte, existen los barrios tradicionales existentes en cada ciudad, que son sectores urbanos cuya actividad principal es la vivienda y no poseen estas condiciones de centralidad urbana (caso del barrio Prado en Medellín con manejo especial de Sector de Preservación).

Figura 6. Centro Histórico - Rionegro, Antioquia

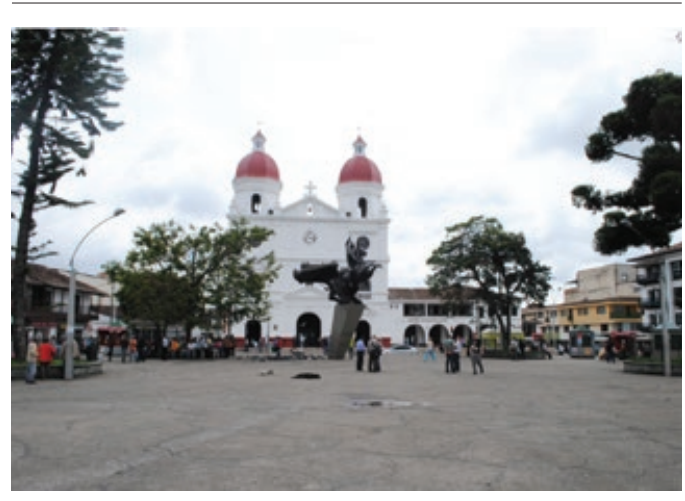

Fuente: Documento de Análisis y Diagnóstico PEMP (2013). Rionegro: Alcaldía Municipal.

Para hacer referencia a un caso específico de incorporación del Centro Histórico a las disposiciones de ordenamiento territo- rial, se toma Rionegro como único municipio de Antioquia con Centro Histórico y POT (categoría con mayor exigencia según la Ley y su Decreto en cuanto a la articulación de estos temas).

El POT vigente de Rionegro fue aprobado por el Acuerdo Municipal 56 de 2011, y en relación con el patrimonio cultural contiene aspectos tales como la delimitación del sector con tratamiento de conservación que incluye el Centro Histórico y su Zona de Influencia, así como el listado de inmuebles individuales declarados BIC. Pero deja a la futura formulación del PEMP la determinación de normas generales, niveles de intervención e incentivos, entre otros temas exigidos por el Ministerio de Cultura en cumplimiento del Decreto 763 de 2009 que reglamenta el Patrimonio Cultural de la Nación de naturaleza material.

Sin embargo, el POT incorpora instrumentos de gestión y financiación aplicables al polígono de conservación que incluye el Centro Histórico y su Zona de Influencia, tales como la integración inmobiliaria, el desarrollo prioritario de predios con parqueaderos y un Fondo Urbano. Como principal instrumento de financiación para el tratamiento de conservación, establece la trasferencia de derechos de construcción y desarrollo al considerar que se limita la transformación de la estructura física de áreas e inmuebles, $\mathrm{y}$, para compensar esta limitación, se crean los derechos transferibles de construcción o desarrollo. Son transferibles porque permiten trasladar el potencial de un inmueble de conservación territarias 32 
a un predio receptor por fuera del polígono de conservación. El otro instrumento de financiación que se estipula en el POT es la compensación en dinero o en su defecto se podrá adquirir el inmueble por su valor comercial.

Con este ejemplo, se estructura una conclusión general basada en aquellas esbozadas en cada aparte, la cual consiste en que la conservación y protección de los Centros Históricos requiere decisiones técnicas que no tienen soporte sin instrumentos de gestión y financiación, por lo tanto, los PEMP no pueden ser los receptores de las carencias de los POT, sino que estos últimos deben incorporar el tema patrimonial.

Además, se concluye que actualmente en Colombia existe un amplio abanico legal y que, para proteger el patrimonio histórico nacional y reconocido por el Ministerio de Cultura, no son suficientes los PDM y POT, reglamentados respectivamente por las Leyes 152 de 1994 y 388 de 1997, sino que se requiere algo más que una aplicación asilada de la Ley de Cultura, tal como ajustar los contenidos de los Componentes Urbanos de los POT, PBOT y especialmente EOT de los municipios que tienen Centros Históricos, para que todas las decisiones sobre el suelo urbano propendan por su protección y adecuado manejo.

Finalmente, se puede concluir que todas las estrategias mencionadas en los distintos apartes proponen utilizar los recursos locales en proyectos coordinados con los propios ciudadanos y así la conservación de los sectores patrimoniales y su aprovechamiento como oferta turística sería una estrategia de competitividad con iniciativas de apropiación cultural y desarrollo social y económico local.

\section{Referencias}

Borja, J. (2003). La Ciudad Conquistada. Madrid: Alianza Editorial.

Colombia, Concejo de Medellín. Acuerdo Municipal número 23 de 2009, por el cual se adopta el Plan Especial de Protección del patrimonio cultural inmueble del Municipio de Medellín (29 de abril de 2009).

Colombia, Concejo de Medellín. Acuerdo Municipal número 46 de 2006, por el cual se revisa y ajusta el Plan de Ordenamiento Territorial para el Municipio de Medellín y se dictan otras disposiciones según la Ley 388 de 1997 y los Decretos Nacionales 879 de 1998 y 4002 de 2004 ( 2 de agosto de 2006).

Colombia, Concejo de Rionegro, Antioquia. Acuerdo Municipal número 56 de 2011, por medio del cual se adopta la revisión y ajuste del Plan de Ordenamiento Territorial para el Municipio de Rionegro (25 de enero de 2011).

Colombia, Congreso de la República. Ley 09 de 1989, por la cual se dictan normas sobre planes de desarrollo municipal, compraventa y expropiación de bienes y se dictan otras disposiciones (11 de enero de 1989).

Colombia, Congreso de la República. Ley 152 de 1994, por la cual se establece la Ley Orgánica del Plan de Desarrollo (15 de julio de 1994).

Margarita María Rodríguez Garcés 
Colombia, Congreso de la República. Ley 388 de 1997, por la cual se modifica la Ley 09 de 1989 y la Ley 03 de 1991 y se dictan otras disposiciones ( 18 de julio de 1997).

Colombia, Congreso de la República. Ley 397 de 1997, por la cual se desarrollan los artículos 70, 71 y 72 y demás artículos concordantes de la Constitución Política y se dictan normas sobre patrimonio cultural, fomentos y estímulos a la cultura, se crea el Ministerio de la Cultura y se trasladan algunas dependencias (7 de agosto de 1997).

Colombia, Congreso de la República. Ley 1185 de 2008, por la cual se modifica y adiciona la Ley 397 de 1997 (Ley General de Cultura) y se dictan otras disposiciones (12 de marzo de 2008).

Colombia, Ministerio de Cultura. (2011). Formulación e implementación planes especiales de manejo y protección, Bienes Inmuebles de Interés Cultural. Bogotá: Ministerio de Cultura.

Colombia, Ministerio de Cultura. Resolución número 1800 de 2005, "por la cual se establece el Plan Especial de Protección del Centro Histórico del Distrito Turístico, Cultural e Histórico de Santa Marta" (30 de diciembre de 2005).
Colombia, Ministerio de Desarrollo Económico. Decreto 879 de 1998, por el cual se reglamentan las disposiciones referentes al ordenamiento del territorio municipal y distrital, y a los planes de ordenamiento territorial ( 13 de mayo de 1998).

Colombia, Presidencia de la República. Decreto 763 de 2009, por el cual se reglamentan parcialmente las Leyes 814 de 2003 y 397 de 1997 modificada por medio de la Ley 1185 de 2008, en lo correspondiente al Patrimonio Cultural de la Nación de naturaleza material ( 10 de marzo de 2009).

Consejo Internacional de Monumentos y Sitios. (2005). Informe final de la reunión sobre conservación y utilización de monumentos y lugares de interés histórico y artístico. Icomos. Recuperado de http://www.icomos.org/

Suárez, G. C. J. (2010). Renovación urbana. ¿Una respuesta al pánico moral? Revista Territorios, 22, 111-124.

Vázquez, B. A. (2007). Teorías y políticas de desarrollo territorial. Investigaciones Regionales, 11, 183-210. 
